\title{
Metabolic effects of long-term oral ingestion of L-histidine in overweight and obese men
}

\author{
Varsha Rajashekar ${ }^{1}$, Frank Hucklebridge ${ }^{1}$, Orla Kennedy ${ }^{2}$ and Adam Cunliffe ${ }^{1}$ \\ ${ }^{1}$ University of Westminster, London, UK and ${ }^{2}$ University of Reading, Reading, UK
}

Animal studies have revealed that histidine (L-hist) intake and neuronal histamine action play a key role in thermoregulation, energy expenditure and feeding behaviour by different mechanisms ${ }^{(1-5)}$. There is a need to reproduce studies of peripheral administration of the essential amino acid L-hist in human subjects to observe any role in key metabolic functions and any possible implications in the treatment of obesity and associated disorders.

The aim of the present study was to examine the effect of L-hist on risk factors for the metabolic syndrome. Eighteen male participants with BMI $>25 \mathrm{~kg} / \mathrm{m}^{2}$ were recruited for an 8-week randomised single blinded placebo-controlled study (intervention $25 \mathrm{mg}$ L-hist $/ \mathrm{kg}$ per d (Lamberts Healthcare, UK); placebo $45 \mathrm{mg}$ Casilan-90 / kg per d (Complan Foods Ltd, UK). Measurements were carried out at 0,4 and 8 weeks and included $\mathrm{BMR}^{6}$, mean skin and core temperature, total cholesterol, HDL-cholesterol, LDL-cholesterol, fasting blood glucose $(\mathrm{FBG})^{7}$, insulin, leptin, NEFA and percentage body fat. Analysis of data was performed using ANOVA.

Results of the study revealed an interesting trend of significantly decreased weight at 4 weeks $(P=0.046)$ and 8 weeks $(P=0.003)$ when compared with baseline weight, irrespective of the type of supplementation. BMR steadily increased over the 8-week period and at a more rapid rate with L-hist supplementation. FBG decreased slightly with L-hist (3.4\% from baseline) compared with the increase (5\% from baseline) observed post placebo intake. An increase in plasma insulin levels was found in the placebo group, with a $6.3 \%$ decrease with L-hist (although this effect was not significant). Plasma NEFA concentrations increased post L-hist intake, indicating elevated lipolysis.

\begin{tabular}{|c|c|c|c|c|c|c|c|}
\hline & \multirow[b]{2}{*}{ Group } & \multicolumn{2}{|c|}{ Baseline } & \multicolumn{2}{|c|}{ Session 2 (4 weeks) } & \multicolumn{2}{|c|}{ Session 3 ( 8 weeks) } \\
\hline & & Mean & SEM & Mean & SEM & Mean & SEM \\
\hline \multirow[t]{2}{*}{ Weight (kg) } & Placebo & 103 & 6.45 & $102 *$ & 6.54 & $102 * *$ & 6.42 \\
\hline & L-Hist & 89.0 & 4.99 & $88.5^{*}$ & 5.09 & $88.3 * *$ & 5.16 \\
\hline \multirow[t]{2}{*}{$\operatorname{BMR}(\mathrm{kJ} / \mathrm{d})$} & Placebo & 8848 & 602 & 8301 & 525 & 8425 & 493 \\
\hline & L-Hist & 7576 & 329 & 7524 & 371 & 7714 & 382 \\
\hline \multirow[t]{2}{*}{ FBG $(\mathrm{mmol} / \mathrm{l})$} & Placebo & 4.91 & 0.15 & 4.93 & 0.22 & 5.15 & 0.24 \\
\hline & L-Hist & 5.33 & 0.34 & 5.39 & 0.23 & 5.15 & 0.16 \\
\hline \multirow[t]{2}{*}{ Insulin $(\mathrm{mU} / \mathrm{l})$} & Placebo & 4.54 & 0.83 & 4.73 & 1.02 & 5.68 & 0.74 \\
\hline & L-Hist & 4.09 & 1.07 & 3.97 & 0.72 & 3.83 & 0.63 \\
\hline \multirow[t]{2}{*}{ NEFA $(\mu \mathrm{mol} / \mathrm{l})$} & Placebo & 967 & 118 & 942 & 145 & 833 & 106 \\
\hline & L-Hist & 821 & 68.0 & 847 & 110 & 850 & 88.5 \\
\hline \multirow[t]{2}{*}{ Leptin (ng/ml) } & Placebo & 20.1 & 5.29 & 15.0 & 2.12 & 15.2 & 2.31 \\
\hline & L-Hist & 11.4 & 2.93 & 10.6 & 2.15 & 10.7 & 2.76 \\
\hline
\end{tabular}

$n 18$. Values were significantly different from those at baseline: $* P=0.046, * * P=0.003$.

Oral ingestion of L-hist may impact on risk factors for the metabolic syndrome. Weight reduction observed post L-Histidine ingestion could be attributed to lower body fat, increased BMR and increased lipolysis (elevated NEFA concentrations) when compared with baseline. The decrease in body fat may also be a factor for improved sensitivity and in turn, reduced fasting blood glucose concentrations. Further studies need to be carried out in humans to understand the exact mechanism of action and implications of L-Histidine supplementation. Further studies need to be carried out in human subjects to understand the exact mode of action and implications of L-hist supplementation.

1. Costenti JP, Boulu P \& Schwartz JC (1973) Agents Actions 3, 177.

2. Sakata T, Ookuma K, Fujimoto K, Fukagawa K \& Yoshimatsu H (1991) Brain Res Bull 27, 371-375.

3. Wada H, Inagaki N, Itowi N \& Yamatodani A (1991) Brain Res Bull 27, 367-370.

4. Sakata T (1995) Obes Res 3, S541-S548.

5. Sakata T \& Yoshimatsu H (1995) Methods Find Exp Clin Pharmacol 17, 51-56.

6. Weissman C, Sardar A \& Kemper M (1990) J Parenter Enteral Nutr 14(2), 216-221.

7. Devreese K \& Leroux-Roels G (1993) Eur J Clin Chem Clin Biochem 31(12), 829-837. 